in that it explains the whole procedure of biological control and its underlying principles. It will obviously prove most helpful to have such information gathered together in so convenient and authoritative a form. There may be differences of opinion here and there on the theoretical side of the subject, but only one criticism of any importance need be raised. On page 25 an erroneous impression is conveyed with reference to the outstanding work of the Hawaiian entomologists and their methods. Probably in no part of the world has greater skill or care been exercised in biological control than in these Pacific Islands, and the successes achieved have been truly remarkable.

\title{
Radio Telephony at the Rugby Station.
}

$\mathrm{P}^{\mathrm{s}}$ ROGRESS is being made rapidly in the development of the Post Office radio transmitting station at Rugby. On the invitation of Sir Thomas Purves, Engineer-in-Chief to the Post Office, who is also president of the Institution of Electrical Engineers, many of the members of the Council of the Institution visited this station on Sept. 30 and were much impressed by the new developments.

In 1927, the first international telephone service designed for connexion with the ordinary telephone subscribers' system was started with one channel between the United States and England. There are now four channels and preparations are nearing completion for a fifth channel. Two of these channels use long waves and three short waves. The short wave systems are cheaper to erect, but they are not so trustworthy as the long waves. For the latter system, there are twelve masts, each 820 feet high, supporting the antennæ. The single side band telephone transmitter G.B.T. is the most powerful radio telephone transmitter in the world. Its wave-length is 5000 metres (60 kilocycles) and its output is equivalent to a broadcast transmitter of 1000 kilowatts. It is wonderful to notice how a current of several hundred amperes is apparently transmitted directly into the ether.

There are now a large number of smaller towers arranged in groups called 'arrays', the heights of which vary from 120 to 180 feet. These towers are used to support the antennæ for the short wave beam telephone services. The arrays are so arranged that the beam is projected in the direction of the great circle joining the transmitting to the receiving station. Three different frequencies are used, depending on the time of day the message is sent, and the message sometimes travels one way round this great circle and sometimes the other way.

The G.B.R. telegraph transmitter is the most powerful one in the world and works at 600 kilowatts and 16 kilocycles. The ninth harmonic of a tuning fork which oscillates at 1777.7 cycles is used to tune the circuit. In the final amplifier stages of G.B.R. each panel contains eighteen cooled anode valves.

By combining both short wave and long wave systems, the Post Office can now provide an effective service to America over the full twenty-four hours. It is not considered possible to operate long wave systems to greater distances than from England to North America. The solution of the problem of providing communication with the Dominions has been obtained by the use of short wave transmission.

In order to prevent unauthorised persons from 'listening in' to the private telephone messages which are now being sent almost continuously, a method has been devised of making the speech as transmitted quite incoherent to the would-be listener. The component parts of the speech are 'scrambled ', that is, they are split up into portions by an electrical device and transmitted in this state, being finally rearranged in their correct form at the distant end. Demonstrations were given to the visitors, through the medium of a loud speaker, of the London side of conversations with New York through the long wave channel. The scrambled speech sounded absolutely meaningless. A somewhat different system of scrambling is adopted in the short wave system. In this case the frequencies of the various sounds are inverted, the high frequency sounds becoming low frequency and vice versa. The sounds produced by the waves in the intermediate stages remind one of barking dogs or crowing cocks.

The Rugby station is used for the ship and shore telephone service. The messages to the Majestic, the Olympic, the Leviathan, and other vessels, are sent out from here.

The electric power required to work the station is obtained from the system of the Leicestershire and Warwickshire Power Company by means of two underground cables, each capable of taking the full load of the station. The cables can be connected to either the Warwick or Hinckley power stations, so that the risk of a failure of the power supply is almost negligible. Short wave services to Australia, South Africa, Canada, India, and the Argentine are either complete or nearing completion. As the site covers 900 acres, there is plenty of room for extension.

\section{Obituary.}

Prof. W. D. Matthew, F.R.S.

$\mathrm{P}$ ALAEONTOLOGISTS, zoologists, and geologists mourn the loss of Dr. William Diller Matthew, professor of palæontology in the University of California, who died on Sept. 24, aged fifty-nine years. For thirty years he shared the charge of the fossil vertebrates in the American Museum of Natural
History, New York, and added greatly to the collection by his own discoveries in the western States. In 1927 he was appointed to the professorship at Berkeley, where he looked forward to extending the palæontological museum of the University of California by renewed activity in collecting fossils on the Pacific border of the American continent.

No. 3180, VoL. 126] 